\title{
Integration Across Knowledge Boundaries During New Product Introduction
}

\author{
Paraskeva WLAZLAK ${ }^{1}$, Daniel HUSSMO and Kristina SÄFSTEN \\ Department of Industrial Product development, Production and Design \\ Jönköping University
}

\begin{abstract}
New product introduction refers to all activities that are required to make a product possible to produce in planned volumes. To ensure smooth new product introduction, product and production developers work in a cross-functional and integrated way. Because of high degree of novelty during new product introduction and interdependencies between those involved knowledge boundaries are created. As prior research argues, different types of knowledge boundaries require different integration processes. For example, integration at a syntactic boundary is established by transfer of domain-specific knowledge across a boundary, while coping with semantic boundary requires a process of translation where learning about the differences and dependencies at the boundary is required. To be able to understand how to integrate product and production development across knowledge boundaries and hence support new product introduction it is important to understand what types of boundaries need to be crossed. To overcome the shortcomings of the prior research, this paper focuses on knowledge boundaries and prerequisites for successful integration in new product introduction. It is based on success stories from three large Swedish companies. This paper addresses transdisciplinary challenges and contributes to literature on boundary crossing during new product introduction and to practice.
\end{abstract}

Keywords. Transdisciplinary engineering, knowledge boundary, new product introduction, integration

\section{Introduction}

Today's trends in manufacturing are associated among others with shorter product life cycles, changing customer requirements, new technology, environmental and safety regulations, high-cost pressure, and increased degree of automation in production. To be competitive in a harsh market it becomes critical for a company to achieve successful new product introduction (NPI) [1][2]. NPI is associated with all activities that are necessary to adapt the product and production system to each other during development of a new product [3]. This among others include activities necessary to secure product manufacturability[1]. Successful NPI is associated with timely start of production and ramping-up the production according to plans in terms of volumes, cost, and quality [4] $[5]$.

To succeed with NPI, companies need to secure integration between product and production development [6][7][8]. Traditionally, companies follow concurrent and transdisciplinary work methodology to reduce the time for NPI [9]. This implies that

\footnotetext{
${ }^{1}$ Corresponding Author, Mail: paraskeva.wlazlak@ju.se.
} 
actors work in parallel with product and production development in an integrated way to bring downstream inputs as early as possible in the product design [5]. Hence, the actors are interdependent to the degree where each actor is constrained by decisions taken by the other party. Furthermore, NPI where new requirements from various stakeholders are implemented is associated with high degree of novelty [1] [10]. Because of different types of domain-specific knowledge, interdependencies and novel circumstances, knowledge boundaries between actors responsible for product and production development are created [11]. Prior research [12][11] recognizes the need for diverse integration processes to cross the different types of knowledge boundaries.

There is limited research as to the type of boundaries that exist during NPI. To be able to understand how to integrate product and production development across knowledge boundaries and hence support NPI it is important to understand what types of boundaries need to be crossed. To overcome the shortcomings of the prior research, this paper focuses on knowledge boundaries and prerequisites for successful integration in NPI. More specifically this paper has two objectives:

1. To describe knowledge boundaries between product and production development during NPI.

2. To outline prerequisites for successful integration of product and production development across knowledge boundaries during NPI.

By combining knowledge of product and production development from the technical discipline with knowledge of boundary crossing from social sciences, and through a combination of academic and scientific goals, two important transdisciplinary issues are addressed [13].

\section{Types of knowledge boundaries and integration}

Boundaries between actors from different domains evolve because of the properties of knowledge, namely difference, dependence, novelty [11]. Difference refers to the dissimilarities of the amount and type of knowledge that is accumulated between actors from different domains specialized in different engineering work; while the dependency implies that actors need to take each other into consideration if they are to meet their goals. Novelty implies that when new circumstances arise, new requirements for the actors from different domains occur and hence no or little common knowledge between them exists. Hence, when the differences, dependencies, and novelty increase, the complexity of a boundary across disciplines also increases. That is why prior research [12] formulate three types of knowledge boundaries that reflect the complexity at a boundary. These knowledge boundaries are referred to as syntactic, semantic, and pragmatic. Associated with the boundaries there are three knowledge integration processes: transfer, translation, and transformation (see Figure 1) [11].

Syntactic boundary implies that common knowledge and shared syntax about differences and dependencies between actors exist and managing this type of a boundary requires transfer of domain-specific knowledge [13]. When novelty increases, the amount of common knowledge and shared vocabulary is reduced, and a semantic boundary occurs between disciplines [14][9]. Novelty makes some difference in the type of domain-specific knowledge (e.g., language, tools, methods) unclear and some meanings ambiguous. In such a case knowledge translation and reaching mutual understanding are necessary. This is achieved by learning about and making explicit new sources of differences [15]. Pragmatic boundary implies that knowledge is 'invested in 
practice' and actors are often reluctant to change their existing knowledge [11]. Crossing this boundary requires not only translation of different meanings but also negotiation of interests [12]. There is a need of transforming knowledge where actors alter the existing knowledge and create new. Prior research [12] acknowledges that an effective transformation process requires existing of both shared syntax and language, as well as shared meaning across the actors.

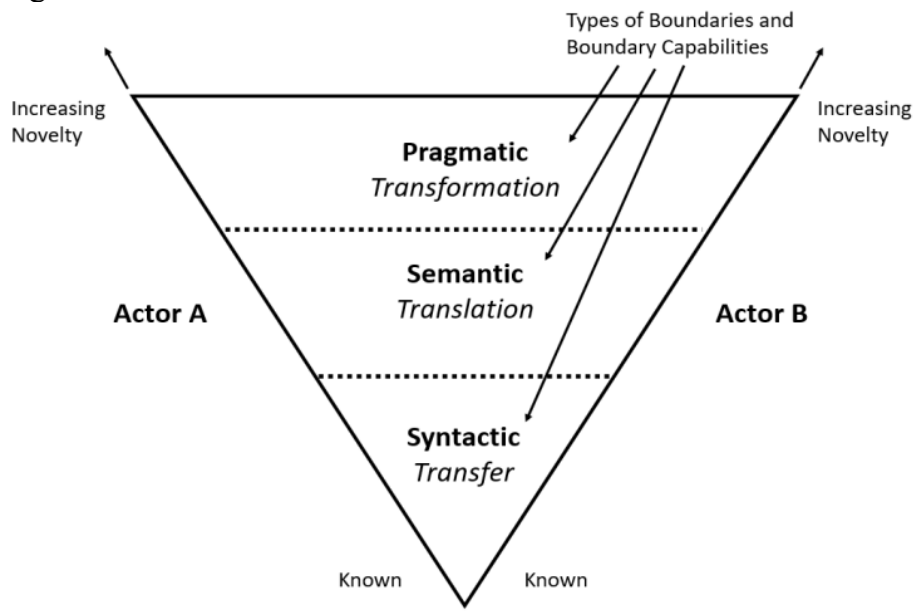

Figure 1. Type of boundaries and integration processes [11]

Several studies indicate that integration of product and production development across knowledge boundary requires objects, spanners, and arenas [1][2]. Research [12] points out that effective objects that support integration at a syntactic boundary need to establish a shared language (vocabulary) which is enough to represent knowledge, like repositories. Effective boundary objects that have the capacity to support knowledge translation are for example standardised formats and methods like design failure mode and effect analysis (D-FMEA) or process failure mode and effect analysis (P-FMEA) [11]. These objects are concrete means that have mutually understood format and structure. Further, they can help to reach knowledge externalization, which using Nonaka's [14] words means making tacit knowledge explicit. Effective objects that can facilitate negotiating and transforming common and domain-specific knowledge used in the past are for example sketches, drawings, prototypes, or simulations [11]. To enhance integration between product and production development, techniques associated with design for manufacture (DFM) and design for assembly (DFA) are used. Among these techniques are for example (1) reviews for assessment of product manufacturability; (2) guidelines for a specific manufacturing process; (3) general guidelines such as standardization, reduction of number of parts in a product for easy for assembly operations [15].

Integration between product and production development is also supported by boundary spanner, that are, individuals that establish linkages, share expertise between domains, and help to resolve conflicts [1]. In the context of NPI, research [16] points out the role of the boundary spanner (the technician) as important to overcome misunderstandings between product and production development. Lastly, encounters are 
meeting points or the arenas between specialized domains where the integration of knowledge take place [1], like the design reviews meetings [15].

\section{Method}

To fulfil the purpose and the objectives of the study, the empirical analysis is based on a multiple case study [17]. The main criteria for selecting the cases were that the companies were from the manufacturing industry, develop and industrialise products in-house, where new products must be rapidly developed. Three large-sized Swedish companies (see Table 1) were selected to participate in the study (from now on referred to Company Armature, Outdoor and Transportation).

Table 1. Overview of the sampled companies

\begin{tabular}{llll}
\hline & Company Armature & Company Outdoor & Company Transportation \\
\hline Industry & $\begin{array}{l}\text { Lighting solutions for } \\
\text { indoor and outdoor } \\
\text { applications }\end{array}$ & $\begin{array}{l}\text { Outdoor power } \\
\text { products }\end{array}$ & $\begin{array}{l}\text { Products for sports and } \\
\text { outdoor activities }\end{array}$ \\
\hline
\end{tabular}

Data was collected by semi-structured, open-ended interviews and through internal company documentation. Key informants were involved in NPI and represented roles such as R\&D, engineering design, production, and project management. Data was collected from September to November 2020. The informants were asked to describe successful stories of integration between product and production development. In addition, various prerequisites which made the integration successful were requested. The interviews were carried out digitally via Microsoft Teams, recorded and transcribed verbatim, which increased the reliability of the study. The informants were able to review the results from the interviews during a workshop and hence the validity of data was strengthened. The data analysis followed the steps prescribed by [18], namely data condensation, data display and conclusion drawing/verification. Contrasting the literature to empirical results was crucial to secure the external validity of the study [17].

The types of boundaries and prerequisites for successful integration are seldom made explicit in the research on NPI. The conceptual model developed by [12] helped to structure our findings.

\section{Case studies}

\subsection{Company Armature}

Company Armature developed both standard and customer specific products. The company strove for automation at the Swedish production site. The managers expressed the need to remove the strict boundaries and improve coordination between product and production development.

Company Armature provided several examples of successful integration between product and production development. Related to a project, one of the informants stated '... I believe the time pressure did a lot, that it was a deadline to relate to and that we could not-absolutely as a new, relatively new player on the market wanted to miss or mess up here’. 
To secure product manufacturability design review meetings involving product developers, quality engineers, purchasing, and production were important. The specialized domains had opportunity to analyse the product and associated risks. Checklist for design reviews was used. Company Armature also had industrialisation reviews where production technicians reviewed the product prior to its introduction in production. During the reviews, a checklist and a prototype were used. Checklist for assembly and painting to secure product manufacturability were used. The design and the industrialization reviews had a purpose to increase understanding between product and production development. The reviews encouraged a dialogue and provided arena for negotiations between the specialized domains.

Early test assemblies with prototypes where the product developer, the production planner and the assembler put together a product were perceived as positive to integrate knowledge between them. The product developer could see what changes had to be made and the assembler could get familiar early with the product and influence the product design. Test assemblies were carried out early in the product design.

To increase the understanding of the product developers for complex production, Company Armature had introduced trainings. During the trainings, production made presentations covering, for example, assembly methods, production methods, work carried out in different cells, as well as critical production aspects that needed to be considered by product developers when developing a new product.

Company Armature expressed that it used guidelines and design books linked to production methods, however, knowledge was mostly exchanged verbally. Product developers had to ask production if their solutions would work. The guidelines were simple related to the cells and the production lines and the information was mostly related to the max/min size and other dimensions but not tolerances. However, as Company Armature explained it was up to each product developer's initiative to use and find out information related to the production aspects.

\subsection{Company Outdoor}

Company Outdoor perceived need to reduce time for NPI and increase efficiency of their production sites. That is why, the company worked with digitalisation and assembly automation.

Company Outdoor indicated that one of the activities to facilitate NPI was a workshop ( 2 to 3 days) involving product and production developers. The purpose of the workshop was to ensure product manufacturability and negotiate changes that had to be made on the product design for cost-effective manufacturing. The first workshop was when the first prototypes were developed. What made the integration successful during these workshops was that the product and production developers felt involved and were familiar with the new product. The use of prototypes was also mentioned as a prerequisite for success.

In general, successful integration required close physical proximity, where product and production developers provided updates and discussed new solutions to various problems during informal meetings. Moreover, keeping the same product and production developers from initial development until product launch was crucial for successful integration. Company Outdoor stated that for successful integration there was a need to allocate a person that was responsible for the integration itself.

According to the project manager, higher levels of assembly automation implied increased need of early integration between product and production development. Early 
integration during initial development gave opportunity to the production developers to set early product requirements related to increased automation and hence prepared the product for automated assembly. Company Outdoor worked with design for automated assembly (DFAA) and developed visual guidelines that helped with mutual understanding between product and production development. Production developers created standards that guided design decisions and communicated the new requirements for automated assembly.

\subsection{Company Transportation}

Company Transportation perceived need to improve alignment between product and production development. It started to use additive manufacturing to develop production tools and moved towards more automated production. The company needed to improve in terms of design for assembly (DFA).

Company Transportation described several examples of successful integration between product and production development. When it came to design for manufacturing (DFM) the company was skilled on a component level. The company had so-called 'knowledge teams' which were cross-functional teams with specialists from different domains. For example, in one knowledge team specialists from production, material, tool specialists, as well as purchasing participated. The idea with knowledge teams was to encourage sharing of experience and competence between individuals who could train each other and spread knowledge between the specializations. This was done to keep knowledge in house. Knowledge was considered person-based and was largely disseminated through meetings (formal and informal). Company Transportation also carried out training for newly employed product developers to increase their knowledge regarding production methods.

To ensure resource efficiency during production preparations physical models and 3D-printed prototypes were important. One informant mentioned 'it makes things much more effective in seeing 'what are the problems and a little opportunity". Prototypes were used for testing but also for communication where one '...see and understand the product in an easier way'. One informant stated that CAD models were useful, but it was even better to have physical models to look at instead of just sitting and discussing. Otherwise, 'people can go from the meeting with different view of what the problem is'.

Company Transportation described several projects were the integration between product and production development was successful. In the first project, there was a strong focus on automation of a product with high volumes. Product developers had close contact with production developers who were dealing with increased levels of automation. The way of work included regular meetings as well as early prototypes (3D printed physical models). In the second project, successful integration was encouraged by the role of a project manager who facilitated discussions between domains. In the third project, the company stated that successful integration was achieved with structured DFA analysis where the goal was to reduce the number of the components and improve the product manufacturability. In the fourth project, junior product developers shared early CAD models with the production developers to get inputs for what was possible and what was not possible to produce. The integration took place during weekly meeting and reconciliation workshops where product and production developers looked at the design and the technical solutions to find the best ones. The integration was facilitated with prototypes. 
In general, Company Transportation expressed that how well different disciplines understood each other was affected by the people's experience and competence and how open they were to the opinions of others. The company further stated that successful integration was influenced by individuals who had the experience and understanding of what challenges related to the product design might occur for the suppliers who had to industrialize and produce a component. It was often the case that the product developers were not aware of problems that suppliers experienced with industrialisation because of a component design. An informant described a situation where he used reference parts (bad and good) and showed them to the product developers so that they could gain understanding 'It is important to be able to communicate with physical parts between product and production development to gain an understanding of things...It's very easy to talk about a part in that way, instead of talking in the air'.

\section{Analysis and discussion}

\subsection{Knowledge boundaries during new product introduction}

The findings of this study indicated that the novel situations in which companies operate were important to describe the complexity of a boundary between product and production development during NPI. Literature on knowledge boundaries [12] describes different types of boundaries but it offers little insight into situations that can cause novelty at a boundary during NPI. To some extent, prior research [5] explains that the novelty level of product and production system (i.e., degree of change) defines the complexity with which product and production developers need to deal with during NPI. Furthermore, the prior research discusses that high novelty and difficult to analyse product/production system fit problems calls for higher levels of integration [5][19]. Higher degree of novelty requires integration through cross-functional teams, while low novelty requires integration via standards, schedules, and plans [5].

A clear pattern turned up among the case studies when looking at the long-term changes and challenges with which companies were faced. The challenges were related to the novelty in terms of new production technology, increased degree of automation, digitalization, and customization. The novelty added complexity at the boundary between product and production development, see Figure 2. The prevailing boundary described by the companies was the semantic boundary [11]. The three companies showed examples of semantic boundaries where changes in the production system increased the knowledge gap between product and production developers. The prevailing examples of semantic boundaries, in comparison to syntactic and pragmatic, was not a surprise. The degree of novelty required translation of differences as well as dependencies that occurred at the boundary between product and production development because of that novelty. There was a need to understand the sources of complexity and uncertainties that affected the integration at a knowledge boundary between the specialized domains. In the context of NPI, a boundary needed to be crossed mainly to secure product manufacturability and the fit of the product and the production system. The case studies corroborate prior research [11] stating that the line between semantic and pragmatic boundary is obscure and unclear. There were few examples of pragmatic boundary where product and production developers negotiated changes that needed to be made on the product design for cost-efficient manufacturing, but focus was mainly on reaching mutual understanding and not on making trade-offs. 


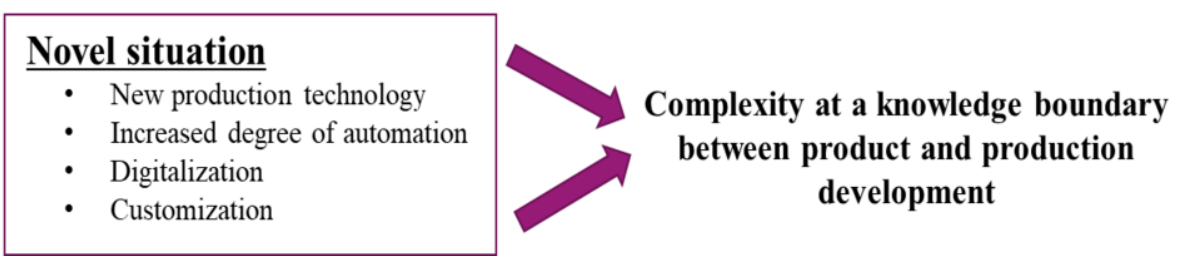

Figure 2. Complexity at a knowledge boundary

\subsection{Prerequisites for successful integration across knowledge boundaries}

The case studies indicated that successful integration across knowledge boundaries was influenced by individuals who were experienced and understood how product design could affect production. The findings indicated that considering determinants of novelty may help in identifying appropriate ways to integrate product and production development across knowledge boundaries. Carlile [12] argues that effective boundary object has the capacity to establish shared context necessary to represent knowledge, provides concrete means to facilitate learning and helps to transform common and domain-specific knowledge. The case studies indicated that for successful integration across semantic and pragmatic boundaries objects such as prototypes, guidelines, checklists, and test assemblies could be used. The use of protypes and test assemblies is in line with prior research [12]. Furthermore, the case studies indicated that guidelines and checklists were also important for integration across semantic and pragmatic boundaries. This could be explained with the fact that knowledge translation and transformation require existence of common lexicon and meaning [11]. Prior research argues that DFM and DFA are important methods that can facilitate the degree of adaptation between product and production system and hence support NPI [5] [1]. In that relation design guidelines and checklist are critical to transfer more routine information [15]. However, the case studies also showed that guidelines and checklists were critical to cross semantic and pragmatic boundaries. In addition to the boundary objects, the case studies indicated that successful integration at semantic and pragmatic boundaries required encounters or arenas which facilitated integration at a knowledge boundary. The encounters indicated in the case studies were review meetings, workshops, weekly meetings, and trainings. Furthermore, in one of the case studies the role of a boundary spanner was pointed as important to cross semantic and pragmatic boundaries. Encounters and boundary spanners in NPI are discussed by [1], however their study does not provide the link between the types boundaries and successful integration across the boundaries. Furthermore, the case studies showed that for successful integration across boundaries, a combination of different ways for crossing the boundary were implemented - for example, a combination of encounter and a boundary object.

The case studies further indicated that prerequisites for successful knowledge integration were not only limited to the use of boundary objects, encounters, and spanners. Successful integration also was determined by external factors that affected these boundary objects and encounters. The case studies indicated that several external factors; open climate, time pressure, time of meeting point during product development, close physical distance; affected the use of boundary objects and encounters. Hence these factors could be considered as important prerequisites for successful integration across knowledge boundaries during NPI. The prerequisites for successful integration across semantic and pragmatic boundaries are summarized in Figure 3. 


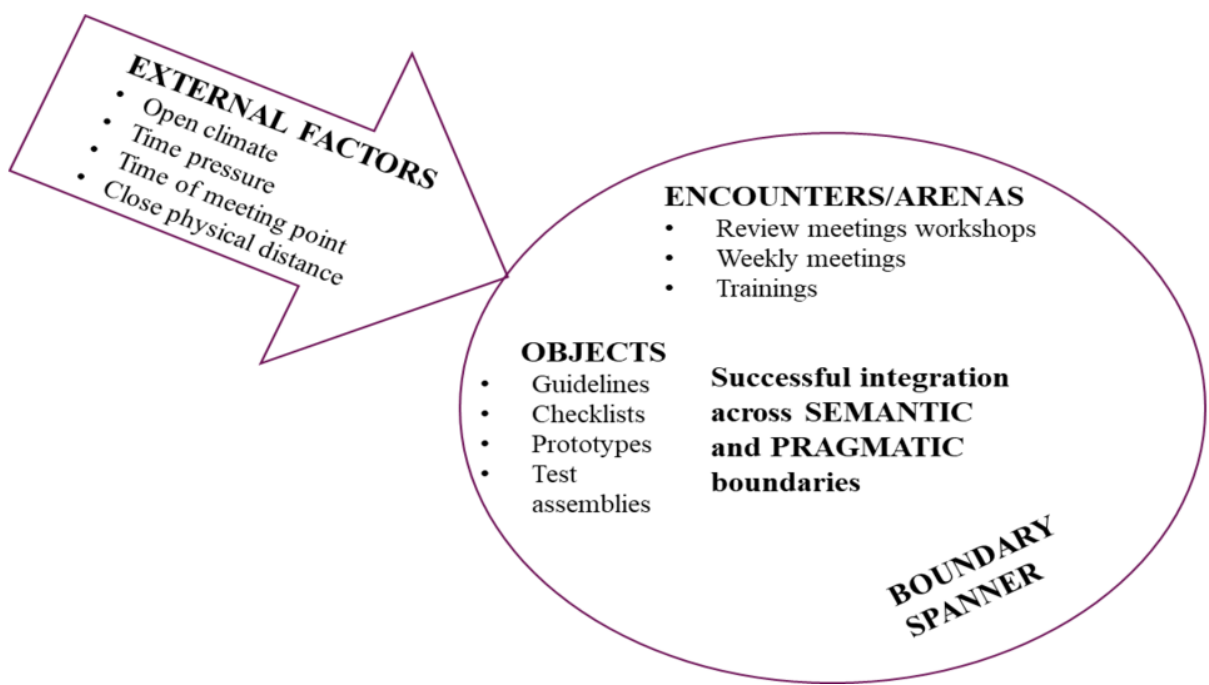

Figure 3. Prerequisites for successful integration across semantic and pragmatic boundaries

\section{Conclusions}

Integrating product and production development across knowledge boundaries during NPI is not an easy task [8]. In this paper, we describe type of knowledge boundaries between product and production development and outline prerequisites for successful integration across them during NPI. This study emphasizes on the need to consider determinants causing novelties and hence different levels of boundary complexity between product and production development during NPI. In today's manufacturing industry many of the novelties are related to the increased automation in production, digitalization and customization which create new requirements for the product and production development. That is why, this study is in line with the prior research [12] and states that sources of the novelty need to be understood for successful integration across knowledge boundaries. Furthermore, in this paper, we extend the literature on boundary crossing during NPI and provide a link between types of knowledge boundaries and successful ways of integration. In addition to the prior research [1] [2][12] this study indicates that prerequisites for successful integration across knowledge boundaries may require the use of not only boundary objects but also encounters and spanners. We further extend the literature on boundary crossing in NPI by proposing that prerequisites for successful integration across knowledge boundaries may also require a combination of boundary objects, encounters, and/ or spanners. Furthermore, prerequisites for successful integration are also associated with external factors to the boundary objects, encounters, and spanners. This study involves more than one discipline integrating engineering from product development (mechanical, electrical, and electronic engineering) as well as production development (production engineering, production planning, quality engineers and purchasing) and discusses how to integrate knowledge across a semantic and pragmatic boundary. Therefore, this study also brings insights into the transdisciplinary literature [9][21]. 


\section{Acknowledgement}

We would like to acknowledge our colleagues in the research project who has contributed to the data collection. We also would like to acknowledge participating industrial partners. This paper is based upon research financed by the Knowledge Foundation.

\section{References}

[1] M. Gustavsson and K. Säfsten, The learning potential of boundary crossing in the context of product introduction, Vocat. Learn. , 2017, Vol. 10, No. 2, pp. 235-252.

[2] P. Wlazlak, Y. Eriksson, G. Johansson, and P. Ahlin, Visual representations for communication in geographically distributed new product development projects, J. Eng. Des. , 2019, Vol. 30, pp. 385404.

[3] M. Bellgran and K. Säfsten, Production development : design and operation of production systems. Springer, New York London, 2010.

[4] S. Fjällström, K. Säfsten, U. Harlin, and J. Stahre, Information enabling production ramp-up, J. Manuf. Technol. Manag., 2009, Vol. 20, No. 2, pp. 178-196.

[5] P. S. Adler, Interdepartmental interdependence and coordination: the case of the design/manufacturing interface, Organ. Sci., 1995, Vol. 6, No. 2, pp. 147-167.

[6] M. Kleinsmann, R. Valkenburg, and J. Buijs, Why do(n't) actors in collaborative design understand each other? An empirical study towards a better understanding of collaborative design, CoDesign, 2007, Vol. 3, No. 1, pp. 59-73.

[7] P. Cash, E. A. Dekoninck, and S. Ahmed-Kristensen, Supporting the development of shared understanding in distributed design teams, J. Eng. Des., 2017, Vol. 28, No. 3, pp. 147-170.

[8] A. Majchrzak, P. H. B. More, and S. Faraj, Transcending knowledge differences in cross-functional teams, Organ. Sci. , 2012, Vol. 23, No. 4, pp. 951-970.

[9] M. Goudswaard, B. Hicks, and L. Newnes, An appraisal and classification of the transdisciplinarity of existing design tools, Advances in Transdisciplinary Engineering, 2020, Vol. 12, pp. 50-59.

[10] P. G. Wlazlak and G. Johansson, R\&D in Sweden and manufacturing in China: A study of communication challenges, J. Manuf. Technol. Manag., 2014, Vol. 25, No. 2, pp. 258-278.

[11] P. R. Carlile, Transferring, translating, and transforming: An integrative framework for managing knowledge across boundaries, Organ. Sci., 2004, Vol. 15, No. 5, pp. 555-568.

[12] P. Carlile, A pragmatic view of knowledge and boundaries: boundary objects in new product development, Organ. Sci., 2002, Vol. 13, pp. 1-21.

[13] N. Wognum, C. Bil, F. Elgh, Peruzzini, M., Stjepandić, J. and W. J. C. Verhagen, Transdisciplinary systems engineering: implications, challenges and research agenda, International Journal of Agile Systems and Management, 2019, Vol. 12, No. 1, pp. 58-89.

[14] I. Nonaka, A Dynamic Theory of Organizational Knowledge Creation, Organ. Sci., 1994, Vol. 5, No. 1, pp. 14-37.

[15] G. Boothroyd, P. Dewherst, and W. Knight, Product Design for Manufacture and Design, 2 nd ed. Marcel Dekker, Inc., New York, 2002.

[16] B. A. Bechky, Sharing meaning across occupational communities: the transformation of understanding on a production floor, Organ. Sci., 2003, Vol. 14, No. 3, pp. 312-330.

[17] C. Voss, N. Tsikriktsis, and M. Frohlich, Case research in operations management, Int. J. Oper. Manag. Prod., 2002, Vol. 22, No. 2, pp. 195-219.

[18] M. Miles, A. Huberman, and J. Saldana, Qualitative data analysis: an expanded sourcebook (4th ed.), SAGE Publications, Thousand Oaks, 2019.

[19] P. Wlazlak, K. Säfsten, and P. Hilletofth, Original equipment manufacturer (OEM)-supplier integration to prepare for production ramp-up, J. Manuf. Technol. Manag., 2019, Vol. 30, No. 2, pp. 506-530.

[20] K. Säfsten, G. Johansson, N.Lakemond, and T.Magnusson, Interface challenges and managerial issues in the industrial innovation process, J. Manuf. Technol. Manag., 2014, Vol. 25, No. 2, pp. $218-239$.

[21] S. Lattanzio, E. Carey, A. Hultin, G. Parry, L.B. Newnes, Transdisciplinarity within the academic engineering literature, International Journal of Agile Systems and Management, 2020, Vol. 13(2), pp. 213-232. 